기술자료

\author{
영국의 시험·검사기관 정도관리 제도 중 현장평가 고찰 \\ 황종연 $^{\dagger} \cdot$ 이혜리 · 고상호 · 전수아 · 김지혜 · 이진주 · 박창희 · 신선경 · 허유정 \\ 국립환경과학원 환경측정분석센터
}

\title{
Quality Control Systems in UK : An On-site Assessments of Testing and Inspection Institutions
}

\author{
Jong Yeon Hwang $\dagger$, Hyeri Lee, Sang Ho Go, Sooa Jeon, Jeehye Kim, Jin Joo Lee, Chang Hee Park, \\ Sun-Kyung Shin, and UJeong Hur
}

Environmental Measurement \& Analysis Center, NIER

Received August 12, 2021 / Revised September 23, 2021 / Accepted September 24, 2021

\begin{abstract}
With reference to the quality standard, ISO/IEC 17025, we conducted on-site assessments of and comparisons between test and inspection institutions in Korea and the UK. The diversity of evaluation methods used 'in the field' within the UK is greater than the range in Korea. Nevertheless, when assessing on-site processes in both countries, it is clear that many aspects of the quality assessment, including the roles of the evaluation committee members, the preparation of documents for evaluation, the opening meeting, the evaluation process in the field, and the closing meeting, occur in a similar order in the UK as in Korea. However, one important difference between the on-site evaluations in Korea and the UK was noted; particularly, in the UK, the level of excellence achieved by the evaluated institution is highlighted during the closing meeting.
\end{abstract}

Key words: ISO/IEC 17025, On-site assessment, Evaluation process

\section{1. 서 론}

$\mathrm{ISO} / \mathrm{IEC} 17025^{1)}$ 를 근거로 하여 시험·검사기관에 대한 현장평가를 실시하는 국가들은 기본적인 틀은 기본적인 틀은 ISO/IEC 17025 를 인용하되 자국의 상황에 맞게 변 형하여 적용하고 있다. 우리나라의 경우는 「환경분야 시 험·검사 등에 관한 법률(이하, 환경시험검사법 $)^{2}$ 제 18 조 의2(시험·검사기관의 정도관리)에 정도관리 업무가 정의 되어 있으며, 같은법 시행규칙 제 17 조의2(정도관리 심의 회 등), 제 17 조의 3 (정도관리 결과의 통보)에서 정도관리 의 시행과 관련된 세부적인 업무를 국립환경과학원장에 게 위임하여 실시하도록 하고 있다. 이에 근거하여 국립 환경과학원에서는 「환경시험·검사기관 정도관리 운영 등에 관한 규정 ${ }^{3)}$ (이하, 정도관리 운영고시)를 제정하여 현장평가 실무와 관련된 내용들을 규정하여 실시하고 있
다. 영국도 ISO/IEC 17025 를 기본으로 한 적용하여 UKAS (United Kingdom Accreditation Service) ${ }^{4}$ 에서 시험·검 사기관에 대한 정도관리 평가규정을 제정하여 현장평가 업 무를 실시하고 있다. 이와 유사하게 미국,5) 호주, () 캐나다 7)의 경우도 자국의 실정에 적합한 형태로 시험검사기관에 대한 현장평가 제도를 운영하고 있다. UKAS는 산업분야, 환경분야, 식품 및 의약품 분야 등 다양한 분야에 대하여 정도관리를 수행하고 있다. 본 연구에서는 ISO/IEC 17025 를 근간으로 한 시험·검사기관의 정도관리에 대하여 $\mathrm{UKAS}$ 의 현장평가 절차를 요약하였으며, 국립환경과학원 의 정도관리 고시에 따른 현장평가 절차를 고찰하였다.

\section{2. 조사 방법}

UKAS는 영국 내 환경시험, 산업 및 생산시험, 의약품

To whom correspondence should be addressed.

Tel: 82-32-560-7904, Fax: 82-32-560-7905, E-mail: hjy6711@korea.kr 
검사기관, 표준물질 생산기관에 대한 인·지정 업무를 수 행하고 있으며, UKAS의 위임을 받은 $\mathrm{CAB}$ (Conformity Assessment Body)에서는 시험·검사 기관의 인·지정 업 무와 관련된 실무를 담당하고 있다. 영국의 시험·검사기 관 인·지정 업무와 관련된 현장평가는 우리나라와 다른 부분도 있지만, 유사한 부분도 많은 것으로 알려져 있다. 본 연구에서는 UKAS에서 수행하고 있는 시험·검사기관 의 인증을 위한 현장평가 과정을 중심으로 하여 현장평 가 종류, 평가위원 분류, 문서자료 준비, 시작회의, 평가 진행, 종료회의 과정을 조사하고, 우리나라의 현장평가와 비교하였다.

\section{3. 결과 및 고찰}

\section{1. 현장평가의 분류}

$\mathrm{UKAS}$ 의 현장평가는 우리나라의 현장평가와 비교할 때 세분화된 부분으로 분류하여 평가를 실시하고 있다. 이러 한 이유는 UKAS에서 수행하는 시험·검사기관에 대한 인 증업무가 다양한 산업 분야에 적용되고 있기 때문이다. 현 장평가의 종류를 분류해 보면 사전평가와 초기평가는 평 가의 적절성을 확인하는 선행평가로 볼 수 있으며, 감시 평가는 정해진 평가주기에 맞춰서 실시하는 평가이다. 범 위확장 평가와 전환평가는 기존에 인정받은 시험분야 외 에 추가적으로 인정 분야 또는 범위를 확장하고자 할 때 실시하는 평가이다. 국립환경과학원에서 실시하는 현장 평가는 3년마다 정기적으로 수행하는 정기 현장평가, 시 험실의 이전에 따른 수시 현장평가, 등록항목의 추가 또 는 시험업무의 확장시에 실시하는 수시 현장평가, 정도관 리 관리상의 문제 발생한 경우에 실시하는 현장평가로 구 분하고 있다. 현장평가 종류의 비교에서는 UKAS의 현장 평가가 세분화된 평가로 구분하여 실시하고 있다.

i 사전평가(Pre-assessment)

대상기관의 초기평가 진행 가능 여부를 확인하기 위한 평가

ii 초기평가(Initial-assessment)

대상기관에 대해 모든 인증 요구사항이 효과적으로 구현되었는지 확인하기 위한 평가

iii 감시평가(Surveillance)

인증주기(1 3년) 동안 인증기준이 유지되고 있는지 확인하기 위한 평가

iv 재평가(Reassessment)

인증주기의 마지막 년도에 모든 인증 요구사항의 준수 여부 확인 i 사전평가(Pre-assessment)

$\mathrm{v}$ 증인평가(Witnessed assessment)

실제적인 적합성 능력을 확인하기 위한 평가(현장방문 또는 별도의 평가방법에 통합되어 진행될 수도 있음).

vi 범위확장(Extension to scope)

$\mathrm{CAB}$ 에 의해 인증된 업무 범위를 변경하거나 확장하기 위해 수행되는 평가

vii 추가방문(Extra visit)

예정된 평가기간 동안 모든 평가를 완료할 수 없는 경우 진행되는 평가 또는 평가 후 미흡사항에 대한 조치 여부를 확인하거나 취약한 분야에 대한 확인 평가

viii 예고 없는 방문(Unannounced visit)

평가 대상기관에 통지하지 않고 불시에 방문하여 진행 하는 평가

ix 전환평가(Transition assessment)

인증된 대상기관이 보유한 인증기준이 변경사항이 발생 한 경우 또는 수정된 요구사항이 충족되었는지 를 확인하기 위한 평가

\section{2. 평가위원 구성}

영국의 시험·검사기관에 대한 현장평가는 UKAS가 지 정하는 $\mathrm{CAB}$ 에 의해 실질적인 업무가 수행된다. $\mathrm{CAB}$ 에 서는 시험실, 검사기관, 인증기관, 검증기관, 표준물질 생 산업체, 숙련도 테스트 제공업체가 모두 포함된다. 평가 에 참여하는 평가위원들은 다음과 같이 구분된다.

1) 평가 관리자(Assessment Manager, $\mathrm{AM}) \mathrm{CAB}$ 인증 프로세스, 감시평가 및 재평가 주기에 대한 전반적인 관리를 담당, 평가관리자는 일반적으로 선임평가자 역할을 하며 평가팀을 선발, 평가계획 및 실시를 총괄 담당

2) 수석 평가자(Lead Assessor, LA) : 평가를 진행고 평 가팀을 지휘하는 평가팀장 역할 수행, 평가팀의 의견 과 인증에 대한 요구사항을 반영하여 평가보고서 작성

3) 기술 평가자(Technical Assessor, TA) : 관련분야 전문지식이 필요한 평가에 참여

4) 기술 전문가(Technical Expert, TEXP) : 공인된 평 가자의 책임하에 평가의 인증범위와 관련하여 특정 한 전문지식 제공

5) 감시 평가자(Lay Assessor) : 평가영역에 대해 사용 자 관점의 의견 제공

$\mathrm{UKAS}$ 의 현장평가에 참여하는 평가위원과 국립환경과 학원에서 실시하고 현장평가의 평가위원들과 비교하면 평 가관리자는 국립환경과학원의 정도관리 총괄 부서장, 수 석평가자는 현장평가 팀장, 기술 평가자 또는 감시평가자 는 각각 분야별 평가위원으로 볼 수 있다. 


\section{3. 문서자료 준비}

문서검토는 현장평가를 신청한 시험·검사기관에서 평 가와 관련된 문서에서는 다음 내용을 담고 있어야 한다. 우리나라의 경우 시험·검사기관에서 기록과 보관을 해 야 하는 시험·검사기록물에 대해서는 환경부 고시인 「환 경분야 시험·검사 업무처리규정(환경부 고시 제2016-166 호)」에서 규정하고 있으며, 관련자료의 보존기간을 설정 하고 있다. 이와 더불어 국립환경과학원의 정도관리 고시 의 제 34 조(정도관리 품질문서 평가)와 제 36 조(시험분야 별 평가)에서는 시험분야별 평가과정에서 평가위원이 검 토해야 하는 기록물에 대하여 상세히 규정하고 있다. 이 들 조항에서 정하고 있는 기록물의 종류에는 기관의 조 직도, 직원의 업무분장서, 시험방법 목록, 장비관리 기록, 표준용액 및 사약목록 기록, 시료관리 기록, 시험성적서, 정도관리 수행기록, 시험실 환경 유지에 관한 기록, 시험 장비의 검정·교정에 관한 기록, 시험성적서의 원자료, 공 정성 유지를 위한 서명, 시험자들의 교육기록 등이다. 우 리나라의 현장평가 과정에서 검토하는 문서도 UKAS의 현장평가과정에서 검토하는 문서와유사함을 알수있다.

1) 품질 매뉴얼 또는 관리 시스템을 설명하는 문서 세트

2) 품질 절차

3) 품질 기록(내부 감사 자료 및 경영진 검토 자료)

4) 시험 능력을 포함한 기술 기록 및 이행 여부

5) 기술 보증 문서

6) 교육 기록

7) 계획 정보

8) 공정성 조치

9) 독립 유형

10) 적합성 평가기관 표준의 관리 시스템 요구사항 옵션

11) 안정성 데이터 및 동질성 데이터

\section{4. 시작회의}

시작회의는 수석평가자에 의하여 진행되며 평가의 진 행과 관련된 사항을 안내하고 전체적인 평가 일정과 아 래 사항들에 대한 내용들을 조율하고 설명한다. 시작회의 는 평가 첫날에 실시하며, 증인평가가 포함되는 경우 수 석 평가자는 추가적인 시작회의를 회의를 주관하거나 $\mathrm{CAB}$ 담당자와 개인적으로 브리핑을 실시하기도 한다. 수 석평가자는 평가과정의 전체를 총괄하고 필요한 경우 조 언을 제공할 수 있도록 평가팀을 관리하며, $\mathrm{CAB}$ 의 직원 은 각 분야별 평가자들에게 경영진으로 부터 업무와 관 련된 담당자를 소개받는다.

1) 평가팀 소개 및 평가위원 역할 소개
2) 평가의 목적과 과정 안내

3) 인증기준 및 평가 범위에 대한 확인

4) 평가계획, 전체적인 업무량, 평가 가이드, 시험실에 대한 정보 확인

5) 과거 평가 시 지적된 시정조치 요구사항에 대한 수행 여부

6) 평가와 관련된 기밀 유지 확인

평가과정의 중점사항은 평가기관에서 적용하는 시험 표 준 및 기타 적용 가능한 요구사항의 충족여부를 확인하 도록 하고 있다. 평가팀은 평가에서 도출된 결과 및 결론 을 위해 객관적인 증거를 수집하고, 평가를 신청한 기관 이 보유한 능력과 중요한 판단을 필요로 하는 경우에는 평가계획을 수정할 수도 있다. 국립환경과학원이 실시하 는 현장평가의 시작회의도 UKAS와 유사한 순서로 진행 된다. 평가팀장이 현장평가의 목적, 대상, 방법, 평가위원 소개, 진행 일정, 시험실 순회평가, 문서평가 과정, 종료 회의 일정등을 소개한다. 현장평가를 받는 시험·검사기관 에서는 기관의 대표자 또는 대리인이 해당기관에 대한 소 개, 직원소개, 시험실에 대한 소개, 시험검사 업무에 대한 전반적인 안내를 하고 있다.

\section{5. 평가진행}

평가를 요청한 기관에서 운영중인 표준의 적용 및 기 타 적용 가능한 요구사항을 충족하는 능력을 확인하기 위 해 평가계획에 따라 진행되며, 평가에서 도출된 결과 및 결론을 뒷받침하기 위한 객관적인 증거를 확인하여야 한 다. 평가과정에서 확인된 사항에 대해 평가팀은 개선조치 또는 보완조치를 요구할 수 있으며, UKAS의 개선조치 보 고서 양식에 기록하고 지적사항의 중요도에 따라서 '필 수' 또는 ‘권장'으로 분류하여 표시하도록 하고 있다. 평 가종료 과정에서 평가팀은 문서기록 검토 결과와 현장평 가에서 수집된 관련 자료와 증거를 분석하는 회의를 수 시로 개최한다. 다음과 같은 중요한 사항에 대해서는 명 확한 설명을 하도록 하고 있다.

1) 인가 또는 인증 범위확장 조건의 충족 여부

2) 모든 필수 요건 충족 여부 확인 및 추가 현장평가 여부

3) 인증/ 범위 확장 충족 여부

4) 인증내용의 일시 중지 또는 부분적 중지(또는 인정서 완전 철회)

또한, 평가과정에서의 지적사항은 객관적이고 정확해 야 하고 지적사항에 대한 조치사항(시정조치)은 공식적인 
자료이어야 하며 공정성을 확보한 자료이어야 한다. 국립 환경과학원에서 실시하는 현장평가는 시작회의 수 시험 실의 순회평가로 시작된다. 시험실 순회평가에서는 시료 접수 창구, 시료 및 자료 보관실, 분야별 시험실, 저울실 및 증류수 공급시설, 그 외 가스 저장실을 포함하여 시험 - 검사와 관련된 구역 등이 포함된다. 품질문서의 평가에 서는 조직도, 업무분장서, 시험방법 목록 및 장비관리 기 록, 표준용액 및 시약목록, 시료관리 기록, 시험성적서의 적절성을 평가하게 된다. 시험분야별 평가에서는 시험담 당자와의 면담, 시료채취, 운반 및 보관에 관한 사항, 시 험방법의 정확한 적용 여부, 시험실 환경, 표준용약 및 시 약의 관리 현황, 장비의 검정 및 교정에 관한 사항, 시험 성적서의 원자료 보관 여부 및 산출 근거의 정확성에 대 한 평가가 이루어지고 있다.

\section{6. 종료회의}

현장평가 종료 전에 평가팀은 수석평가자의 주관으로 종료회의를 개최한다. 종료회의의 참석자는 대표자, 시험 업무 담당팀, 기술영역의 담당팀이 참석하도록 하고 있 다. 평가팀의 수석 평가자는 다음 사항들에 대하여 설명 을 하여야 한다.

1) 평가 범위에 대한 검토내용 제공

2) 각 팀원의 평가 결과에 대한 요약 제공

3) 우수한 성능 영역(우수한 분야) 강조

4) $\mathrm{CAB}$ 의 주요 관심 영역(강점) 강조

5) 기밀 유지 작업(중요성) 강조

6) 평가가 샘플링 작업인 경우 평가 중에 식별되지 않은 부적합이 존재 가능성 설명

7) 인증의 부여, 연장, 갱신의 인증유지에 대한 안내

8) 지적사항을 종결하기 위한 추가 제출자료 안내

9) 지적사항을 종결하기 위한 추가 제출자료 제출기한 안내

10) 평가 보고서 및 개선조치 보고서 발행을 위한 합의 사항

11) 다음(추후) 진행 단계 안내

UKAS의 현장평가 종료회에서 부각되는 부분은 평가 를 받는 기관의 우수한 점에 대한 강조를 하고 있다는 점 이다. 이와 관련해서 평가 분야 중 타 시험·검사기관에 비해서 우수한 점을 부각시켜 주며, 향후 시험·검사기관 의 발전을 위한 방향에 대한 의견도 제시하고 있다. 또한, $\mathrm{CAB}$ (Conformity Assessment Body)의 관점에서도 평가 를 신청한 기관의 강점과 약점에 대한 의견을 제시하여
통하여 향후 도래할 수 있는 위험 사항에 대해서도 안내 를 해주고 있다. 국립환경과학원에서 실시하는 종료회의 에서도 온라인으로 작성한 평가표에 대한 설명과는 별도 로 분야별 평가위원이 개선이 필요한 사항에 대해 안내 를 하고 있으며, 타 시험·검사기관에 비하여 시설 및 장 비운영 부분에 대하여 우수한 점을 강조하는 부분들은 $\mathrm{UKAS}$ 와 비슷하다고 할 수 있다.

\section{4. 결 론}

ISO/IEC 17025 를 근간으로 한 우리나라의 정도관리 현 장평가와 UKAS의 현장평가를 비교한 결과, 시험·검사 기관으로서 최초 인정을 위한 현장평가와 시험·검사기관 으로서 인정을 받은 후 받게되는 현장평가의 종류는 우 리나라에 비하여 UKAS가 다양한 방법을 적용하고 있 다. 또한, 평가에 직접 참여하는 평가위원의 분류에서도 우리나라와 비슷한 형태로 분류되어 있지만 좀 더 세분 화된 평가위원 그룹으로 세분하여 진행하고 있다. 전체적 인 평가과정을 우리나라와 비교해 보면 문서자료 준비, 시 작회의, 평가진행 과정, 종료회의도 우리나라의 현장평가 와 유사한 부분이 있으며, 영국의 경우는 종료회의 시 평 가를 받는 기관에 대한 우수한 점을 부각시켜 주고 있다.

\section{감사의 글}

이 연구는 국립환경과학원 연구사업(과제번호: NIER2019-01-03-004)로 수행되었으며, 연구진들은 국립환경과 학원의 지원에 깊은 감사를 드립니다.

\section{참고문헌}

1. ISO/IEC 17025, General requirements for the competence of testing and calibration laboratories, ISO, Geneva, 2015.

2. 환경부, 「환경분야 시험·검사 등에 관한 법률」, 2021.

3. 국립환경과학원, 「환경시험·검사기관 정도관리 운영등에 관한 규정」, 2021.

4. UKAS, General Principles for the Assessment of Conformity Assessment Bodied by the United kingdom Accreditation Service, 2019.

5. NIST, National Voluntary Laboratory Accreditation Program, 2016.

6. NATA, NATA procedures for accreditation, 2019.

7. CALA, A06-CALA Accreditation Program, Policies and Procedures, 2019. 